\title{
Assessment of direct radiological risk and indirect associated toxic risks originated by Coal-Fired Power Plants
}

\author{
M.L. Dinis ${ }^{1}$, A. Fiúza ${ }^{1}$, J. Góis ${ }^{1}$, J.S. de Carvalho' ${ }^{1}$ and A.C.M. Castro ${ }^{1,2}$ \\ ${ }^{1}$ Geo-Environment and Resources Research Center (CIGAR), Engineering Faculty, Porto \\ University (FEUP), R. Dr. Roberto Frias, 4200-465 Porto, Portugal \\ ${ }^{2}$ School of Engineering, Polytechnic of Porto (ISEP), R. Dr. António Bernardino de Almeida, \\ 431, 4200-072 Porto, Portugal
}

\begin{abstract}
Over the past few decades there has been some discussion concerning the increase of the natural background radiation originated by coal-fired power plants, due to the uranium and thorium content present in combustion ashes. The radioactive decay products of uranium and thorium, such as radium, radon, polonium, bismuth and lead, are also released in addition to a significant amount of ${ }^{40} \mathrm{~K}$.

Since the measurement of radioactive elements released by the gaseous emissions of coal power plants is not compulsory, there is a gap of information concerning this situation. Consequently, the prediction of dispersion and mobility of these elements in the environment, after their release, is based on limited data and the radiological impact from the exposure to these radioactive elements is unknown.

This paper describes the methodology that is being developed to assess the radiological impact due to the raise in the natural background radiation level originated by the release and dispersion of the emitted radionuclides. The current investigation is part of a research project that is undergoing in the vicinity of Sines coal-fired power plant (south of Portugal) until 2013. Data from preliminary stages are already available and possible of interpretation.
\end{abstract}

\section{INTRODUCTION}

Over the past few decades there has been some discussion about the elevated natural background radiation in areas near to coal-fired power plants. Coal contains trace quantities of the naturally occurring radionuclides like uranium (1 to $10 \mathrm{ppm}$ ) and thorium (3 to $25 \mathrm{ppm}$ ), as well as their radioactive decay products and ${ }^{40} \mathrm{~K}$. When coal is burned, minerals, including most of the radionuclides, do not burn and concentrate in the ash. These materials increase the radiation output. They may also accumulate in the environment or be continually dispersed in millions of tons of coal combustion by-products.

As radiological impact is usually considered to be related to nuclear energy or atomic bombs, most of the research on radiation protection has been focused on artificial radionuclides and radioactive waste. Far less attention has been paid to the risk caused by the exposure to natural materials in which radioactive elements concentration is enhanced.

Since radioactive elements from coal power plants emissions are not obligatory measured parameters, there is no measured data or concentration estimative for the radioactive elements released. Consequently, predicting dispersion and mobility of these elements in the environment, after their release, is based on limited data and the radiological impact from the exposure to these radioactive elements is most of the times unknown.

People living near coal power plants may be exposed to increasing quantities of radioactive isotopes through air, water movement and food chain transfer. Because the half-lives of these radionuclides are practically infinite in terms of human lifetimes, the accumulation of these species in the biosphere is directly proportional to the length of time that a quantity of coal is burned.

The Oak Ridge National Laboratory (ORNL) gives statistics on the levels of radioactive material given off by a coal fired plant: to run an average $1000 \mathrm{MW}$ coal-fired power plant, it is needed to burn 
about 4 Mton of coal which contains 5.2 ton of ${ }^{238} \mathrm{U}, 12.8$ ton of radioactive ${ }^{232} \mathrm{Th}$ and 0.22 ton of radioactive ${ }^{40} \mathrm{~K}$. It was also found by the National Council on Radiation Protection \& Measurements [1], [2] [3] that the radiation exposure from an average $1000 \mathrm{MW}$ power plant comes to an individual dose of $4.9 \mathrm{~Sv} / \mathrm{yr}$ for coal-fired power plants and of $0.048 \mathrm{~Sv} / \mathrm{yr}$ for nuclear-fired power plants.

This paper describes the methodology that is being developed to assess the radiological impact due to the raise in the natural background radiation level originated by the release and dispersion of the emitted radionuclides. The current investigation is part of a research project that is undergoing in the vicinity of a coal-fired power plant located in the south of Portugal (Sines), until 2013. The project proposes to develop an integrated risk assessment (physical, chemical and radiological) resulting from the dispersion of particulate matter, heavy metals and radionuclides from Sines coal power plant releases. The great challenge in this approach is to include simultaneously in the risk analysis the exposure to radioactive elements contained in the ashes produced by the combustion and the effects of the hazardous heavy metals commonly found in combination with the radioactive elements but that can be originated by some other industrial activities in the region.

The development of such a mixed comprehensive model is an arduous and difficult task. Nevertheless the research expects to propose at least a preliminary model. This paper presents the methodology adopted to accomplish the proposed tasks. Data from preliminary research stages are already available and susceptible to interpretation.

\section{METHODS AND MATERIALS}

\subsection{Study area}

Sines coal-fired power plant is located in the southwest coastline of Portugal, at $6 \mathrm{~km}$ south-east from Sines and about $150 \mathrm{~km}$ south from Lisbon. It is a conventional coal-fired power plant with four coal fired units, each one with an electrical energy output of 314 MW [4]. The first unit started working in 1985 and the last one in 1989. The power plant operates with efficiency in the range of 32 to $35 \%$. The facility has two operational stacks both with $225 \mathrm{~m}$ height and supplies about 20 to $25 \%$ of all electrical energy produced in Portugal. The power station burns bituminous coal as a primary fuel, imported from many different countries.

\subsection{The methodology}

Environmental radiation monitoring in the vicinity of Sines coal-fired power plant will be used primarily to determine the variability in measured background exposures to determine the plant's contribution, both qualitatively and quantitatively, on the background radiation level.

The research works involves the collection of local data (radiological, chemical and physical) that may be originated by the releases from Sines coal power plant and, in a later stage, the modeling of environmental transport, dispersion and fate of coal dust ashes containing radionuclides and some heavy metals and, finally, the study of the resident population potential exposure. Part of the work is being developed in the field and another part is being developed in the laboratory with soil and vegetation samples collected at pre-selected sampling points.

Sampling campaigns for dust fallout, metals and radioactive elements are being carried out in the study area twice a year, since September 2010. A total of 40 relevant sampling points were established for this area. Particulate matter is being monitored with appropriated dust collectors: 13 urban and suburban airborne dust sedimentation plates were placed inside the inner circle around the plant and 27 other were placed in the outer subarea. The first survey of heavy metals was already performed using a portable X-ray dispersive energy fluorescence spectrometer. A second one is undergoing during April of 2011. Radioactive measurements will be done using a gamma spectrometer with energy discrimination, 


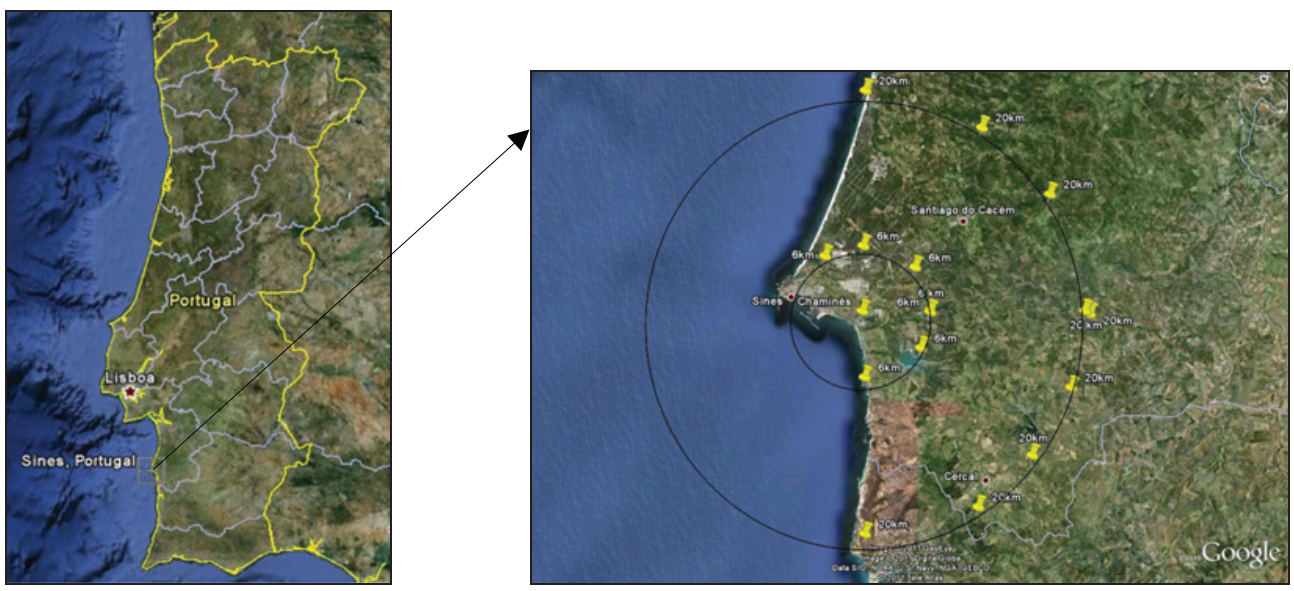

Figure 1. Sampling area around Sines coal power-fired power plant (Google Earth).

based on a high purity germanium detector, allowing for radionuclides identification. This will be carried out either in-situ or in laboratory with the collected soil samples.

\subsubsection{Preliminary information collection and compilation}

As a first step of the proposed methodology, local meteorological conditions are being studied using a portable self standing station placed near the coal power plant since September 2010. Data on wind patterns (wind velocity, direction and profile), precipitation, solar radiation, relative humidity, atmospheric pressure and ambient temperature are being collected every 10 minutes. This information is being stored in a database.

Data on this particular source emission were also compiled from the available legal data of the following European Database: European Pollutant Release and Transfer Register (E-PRTR). Others sources of local information referring to the study site, such as existing Environmental Impact Assessments, were also consulted and analysed.

\subsubsection{Sampling areas}

The area of influence and, consequently, the sampling area were defined considering the possible enhanced external irradiation on the people living in the neighborhood of the coal thermal power plant, up to distances of $20 \mathrm{~km}$. Thus, the sampling area was divided into two subareas: the inner, with higher sampling density and urban and suburban characteristics, inside a $6 \mathrm{~km}$ circle centered in the stacks, and an outer subarea, mainly rural, with lower sampling density within a radius of $20 \mathrm{~km}$ (figure 1). Same sampling procedures were performed at the sampling points selected as a control, away from possible influence of the power plant. The values from these control points are very important as they represent the "zero" background concentration level, meaning without the influence of the power plant.

\subsubsection{Sampling and monitoring dust fallout}

The two sampling areas were selected to assess the spatial heterogeneity and deposition flux of dust fallout and to quantify the atmospheric fallout a passive collection system according to the norm NF X43-007 (1973) was followed. This collection system consists of a $50 \mathrm{~cm}^{2}$ stainless steel slide horizontally fixed at a defined height above the ground with a silicone cover to trap dust fallout. 
Two annual sampling campaigns were established in order to collect variable data according to potential seasonal meteorological patterns considering, in particular, rainy or dry atmospheric conditions.

During the first campaign, from September to October 2010, 40 collectors were placed on the sampling area, at about 3 meters above the ground for a period of one month. This height above the ground was adopted in order to assure that the collectors were recovered after the collecting period without being damaged. The collectors were covered with hidrosilicone oil (Polydimethylsiloxane, CAS 63148-57-2). In October of 2010, ten collectors were placed and left for approximately six months to collect enough material for qualitative analyses. The strategy was to place 2 slices in 5 selected sampling points.

During the second campaign, from April to May of 2011, 40 other collectors were placed in the same sampling points. A month period was chosen for deposition flux determination according to the previous procedure and the norm NF X43-007. At the same time 28 slides with a deposition area of $200 \mathrm{~mm}^{2}$ were placed and left for a period of six months to collect enough material to an accurate determination of sampling volume and of heavy metal concentration. The aerosols attach to the resin are removed after the period of deposition. The slices are then rinsed with an organic solution at the laboratory. The solvent is filtered in a glass filtration system over a $0.22 \mu \mathrm{m}$ cellulose membrane filters with $47 \mathrm{~mm}$ diameter. Filters are dried and weighted to later obtain dust quantity expressed in weight per area per time $\left(\mu \mathrm{g} \mathrm{m}^{-2} \mathrm{~d}^{-1}\right.$ or $\left.\mathrm{g} \mathrm{m}^{-2} \mathrm{yr}^{-1}\right)$ which represents the dust fallout deposition flux.

Dust heavy metals content, in particular, $\mathrm{Cd}, \mathrm{Pb}, \mathrm{As}, \mathrm{Hg}$, are analyzed by digesting the filters with Acqua Regia $\left(\mathrm{HCl}\right.$ and $\mathrm{HNO}_{3}$ ) following the norm NF ISO 11466 (1995). The next steps will be to determine the chemical composition by Inductively Coupled Plasma (ICP) and size and morphology particles by Electron Probe Micro-Analysis (EPMA) in one stage and to determine radiological composition, quantitative and qualitative, in another stage. Micro-Analysis is used for particulate matter characterization, from the urban and suburban atmosphere of the study site. The purpose is to provide an analysis of different types of airborne particles such as chemical form and microstructure, as well as a morphological and compositional characterization. Taken as an example the possible presence of aluminosilicates particles with a spherical morphology, this is a good indication of fly-ash particles from coal-fired utilities that were submitted to high combustion temperatures.

\subsubsection{Sampling metals in the influence area}

Heavy metals measurements in both sampling campaigns were performed with a portable analytical $\mathrm{X}$-Ray dispersive energy fluorescence spectrometer. Two measurements were done in situ and repeated in the laboratory with soil samples collected at each sampling point. About 12 to 15 different elements were detected for each sampling point: $\mathrm{Al}, \mathrm{As}, \mathrm{Ba}, \mathrm{Ca}, \mathrm{Cd}, \mathrm{Cr}, \mathrm{Cu}, \mathrm{Fe}, \mathrm{K}, \mathrm{Hg}, \mathrm{Mo}, \mathrm{Mn}, \mathrm{Na}, \mathrm{Pb}, \mathrm{Rb}, \mathrm{S}$, $\mathrm{Sr}, \mathrm{Ti}, \mathrm{Zn}$ and $\mathrm{Zr}$. A more detailed analysis with ICP and EPMA will be the next step to complete soil characterization.

\subsubsection{Sampling radioactive elements in the influence area}

This task hasn't been accomplished yet. Nevertheless, preliminary laboratory measurements identified ${ }^{40} \mathrm{~K},{ }^{232} \mathrm{Th},{ }^{226} \mathrm{Ra},{ }^{234} \mathrm{Th},{ }^{212} \mathrm{~Pb}$ and ${ }^{214} \mathrm{~Pb}$ in soil samples collected at the study site. It is still necessary to quantify the activity of the identified radionuclides as well as the uncertainty associated.

Radioactive elements measurements are to be conducted at the same sampling points with a portable gamma radiation spectrometer with energy discrimination (FALCON 5000). This portable equipment is a radionuclide identifier (RID) based on a High Purity Germanium (HPGe) detector. The spectrum data will be analyzed using the software Genie 2000 (Canberra) in order to discriminate the main natural emitting nuclides, ${ }^{238} \mathrm{U},{ }^{232} \mathrm{Th}$ and ${ }^{40} \mathrm{~K}$, as well as some other nuclides such as ${ }^{226} \mathrm{Ra}$ or ${ }^{210} \mathrm{~Pb}$. 
Same sampling measurements procedures are to be performed at all sampling points including those selected as control, away from possible influence of the power plant. The values from this control sampling points also represent the "zero" background radiation level without the influence of the power plant.

At the end of all sampling campaigns, chemical analysis and radioactive elements measurements compilation will be done for the subsequent data analysis and further models development. For now, the next step is to carry out the laboratory gamma spectrometry measurements of the collected soil samples in the two campaigns. Following analytical procedures before laboratory measurements, these samples were already grinded, dried at $100^{\circ} \mathrm{C}$ for $24 \mathrm{~h}$ and each sample was packed in a sealed PVC container and stored for a period of one month to ensure radioactive equilibrium between ${ }^{226} \mathrm{Ra},{ }^{232} \mathrm{Th}$ and their decay products. An average $0.25 \mathrm{~kg}$ of soil per sample will be used in gamma spectroscopy analysis.

\subsubsection{Sampling heavy metals and radioactive elements in vegetation}

Plant samples were taken randomly across the study area during September 2010 in each sampling point. The same procedure was established in the sampling campaign that is being carried out in April of 2011. These samples were frozen until further analytical procedure. In a first approach, the methodology to be adopted in this task consists in washing the samples under running tap water to remove adhere soils from roots. Leaves are to be washed separately and the remaining solid material filtered to further analysis. Both leaves and roots are to be dried for $48 \mathrm{~h}$ at $80^{\circ} \mathrm{C}$. The dried samples are crushed using an agate mortar and pestle set, then sieved at $2 \mathrm{~mm}$ and transferred to polyethylene containers for storage until later analysis [5].

\section{RESULTS AND DISCUSSION}

In what concerns to preliminary information collection and compilation, data is being continuously collected from the meteorological station implemented in the study area located at south of the coal power plant. It was already possible to extract some information about the collected data, for instance, the prevalent wind direction is $\mathrm{NW}$, wind velocity is relatively constant during all year; the highest values occur in N-NW and SW sectors in winter season [6].

Data from 1971 to 1990 referring to Sines meteorological station was also compiled from others available studies [7]. Average monthly data for temperature, rainfall, relative humidity, insulation as well as wind velocity, direction and frequency were extracted.

Data concerning to pollutant releases to air from Sines Power Plant were extracted from the European Pollutant Release and Transfer Register database (E-PRTR) [8]. The data refers only to required legal constraints; there are no records for radiological parameters in this official European database. The most recent values refer to the year of 2008 (Table 1).

So far data on deposition flux was obtained for the first sampling campaign. Dust fallout flux was calculated according to the norm NF X43-007 and showed a high variability among the sampling points. The values ranged from $65.94 \mathrm{~g} \mathrm{~m}^{-2}$ year ${ }^{-1}$ to $4.20 \mathrm{~g} \mathrm{~m}^{-2}$ year ${ }^{-1}$. The annual flux of dust fallout was in average $22.51 \mathrm{~g} \mathrm{~m}^{-2}$ year ${ }^{-1}$ with a standard deviation of $15.66 \mathrm{~g} \mathrm{~m}^{-2}$ year $^{-1}$. A value of $17.85 \mathrm{~g} \mathrm{~m}^{-2}$ year $^{-1}$ was calculated for geometric mean. The slices that were left in the study area for a longer period of time (October 2010/April 2011) collected, as expected, higher material (Table 2).

For soil survey the most relevant elements for this research detected by $\mathrm{X}$ - ray fluorescence include $\mathrm{As}, \mathrm{Cu}, \mathrm{Hg}, \mathrm{Pb}$ and $\mathrm{Zn}$ in both areas, within $6 \mathrm{~km}$ and $20 \mathrm{~km}$ from the center of the coal power plant (Table 3).

Mercury was not identified in the measurements carried out in the area within the radius of $20 \mathrm{~km}$ from the coal power plant and there was only one single reading for nickel and selenium (not presented in Table 3) in the same area. 
Table 1. Sines coal power plant releases for the year of 2008 [8].

\begin{tabular}{l|c}
\hline Releases to Air & Total \\
\hline Arsenic and compounds (as As) & $31.0 \mathrm{~kg}$ \\
Chlorine and inorganic compounds (as $\mathrm{HCl})$ & $21.8 \mathrm{t}$ \\
Carbon monoxide $(\mathrm{CO})$ & $659 \mathrm{t}$ \\
Carbon dioxide $\left(\mathrm{CO}_{2}\right)$ & $6,150,000 \mathrm{t}$ \\
Fluorine and inorganic compounds (as $\mathrm{HF})$ & $55.9 \mathrm{t}$ \\
Mercury and compounds (as Hg) & $209 \mathrm{~kg}$ \\
Nitrous oxide $\left(\mathrm{N}_{2} \mathrm{O}\right)$ & $98.3 \mathrm{t}$ \\
Nickel and compounds $($ as $\mathrm{Ni})$ & $271 \mathrm{~kg}$ \\
Nitrogen oxides $\left(\mathrm{NO}_{\mathrm{x}} / \mathrm{NO}_{2}\right)$ & $14,900 \mathrm{t}$ \\
Particulate matter $\left(\mathrm{PM}_{10}\right)$ & $394 \mathrm{t}$ \\
Sulphur oxides $\left(\mathrm{SO}_{\mathrm{x}} / \mathrm{SO}_{2}\right)$ & $17,100 \mathrm{t}$ \\
Zinc and compounds $($ as $\mathrm{Zn})$ & $265 \mathrm{~kg}$ \\
\hline
\end{tabular}

Table 2. Weight dust fallout collected for two different periods of time.

\begin{tabular}{c|cc}
\hline $\begin{array}{c}\text { Sampling } \\
\text { point } \mathbf{N}^{o}\end{array}$ & $\begin{array}{c}\text { Weight dust fallout (g) } \\
\text { (deposition time 33 days) }\end{array}$ & $\begin{array}{c}\text { Weight dust fallout (g) } \\
\text { (deposition time 167 days) }\end{array}$ \\
\hline 2 & 0.0085 & 0.0103 \\
7 & 0.0047 & 0.0061 \\
12 & 0.0030 & 0.0177 \\
14 & 0.0035 & 0.0056 \\
16 & 0.0020 & 0.0060 \\
\hline
\end{tabular}

Table 3. X-Ray fluorescence results for relevant elements.

\begin{tabular}{c|c}
\hline Metals & Average $\pm \sigma(\mathbf{p p m})$ \\
\hline Area within radius $6 \mathbf{~ k m}$ from coal power plant & \\
\hline $\mathrm{As}$ & $88.87 \pm 27.86$ \\
$\mathrm{Cu}$ & $57.00 \pm 13.89$ \\
$\mathrm{Hg}$ & $15.50 \pm 7.78$ \\
$\mathrm{~Pb}$ & $33.85 \pm 27.19$ \\
$\mathrm{Zn}$ & $66.03 \pm 50.67$ \\
Area within radius $\mathbf{2 0} \mathbf{~ k m}$ from coal power plant & \\
$\mathrm{As}$ & $107.78 \pm 28.74$ \\
$\mathrm{Cu}$ & $56.33 \pm 18.28$ \\
$\mathrm{Hg}$ & $\mathrm{n} . \mathrm{d}$. \\
$\mathrm{Pb}$ & $23.35 \pm 13.40$ \\
$\mathrm{Zn}$ & $70.00 \pm 87.00$ \\
\hline
\end{tabular}

Metals content in soils for $\mathrm{As}, \mathrm{Cu}, \mathrm{Hg}, \mathrm{Pb}$ and $\mathrm{Zn}$, were compared with legal legislation limits values for the maximum permissible concentration according to soil use: agricultural, residential or industrial. Comparing the available measurements from the first campaign with the Canadian Soil Quality Guidelines for the Protection of Environmental and Human Health [9] arsenic is the only metal which is in average above the guidelines for all types of land use $\left(12 \mathrm{mg} \mathrm{kg}^{-1}\right)$. Mercury is also above the Canadian guidelines for agricultural and residential soils $\left(6.6 \mathrm{mg} \mathrm{kg}^{-1}\right)$ in the area within the $6 \mathrm{~km}$ 
from the coal-fired power plant. Nevertheless, we should have in mind that there are only two readings available for this metal.

\section{CONCLUSIONS}

The methodology that is being followed to assess the direct radiological risk and indirect associated risks originated by coal power plants is presented above. During 3 years a research study is being conducted in the vicinity of Sines coal-fired power plant, located in the south of Portugal. Seasonal sampling campaigns are being carried out. Two sampling campaigns were already accomplished between 2010 and 2011. The global study will be complete in 2013.

During 4 weeks dust fallout was collected at 40 sampling points inside the area within a $6 \mathrm{~km}$ and $20 \mathrm{~km}$ circle around the coal power plant. The sampling points were also used to perform metal and radiological measurements. Sampling and collecting procedure for dust fallout and metals were repeated twice a year so far. Radiological measurements are being carried out by gamma spectrometry at the laboratory with soils samples collected at the same time as metals survey.

The methodology adopted and the tasks accomplished so far allowed us a comparison between different seasonal climatic conditions, as well as spatial comparison between the areas influenced by coal power plant; the data obtained in different influence areas allow a comparison between urban and rural dust fallout as well as the determination of temporal trends at the study site accomplished by seasonal samplings campaigns. Further work will include the statistical and geostatistical analysis of the analytical and radiological data that is being collected in the sampling campaigns at the study site.

\section{Acknowledgments}

This work is being supported by FEDER grants through the COMPETE (Programa Operacional Factores de Competitividade) and by national grants through the FCT (Fundação para a Ciência e Tecnologia) namely via the project FCOMP01-0124-FEDER-009745 (FCT reference: PTDC/ECM/100735/2008).

\section{References}

[1] NCRP - National Council on Radiation Protection, Public Radiation Exposure From Nuclear Power Generation in the U.S. Report No. 92 (1987) 72-112.

[2] NCRP - National Council on Radiation Protection, Exposure of the Population in the United States and Canada from Natural Background Radiation Report No. 94 (1987) 90-128.

[3] NCRP - National Council on Radiation Protection, Radiation Exposure of the U.S. Population from Consumer Products and Miscellaneous Sources Report No. 95 (1987) 32-36 and 62-64.

[4] Cianci V., Coppola D., Sunk W., Dry Ash Collection at Coal Fired Power Plants and Potential for WTE Facilities, Proceedings of the 15th Annual North American Waste to Energy Conference NAWTEC15, Miami, Florida USA, May 21-23 (2007) 41(12).

[5] Douay F., Roussel H., Pruvot C., Loriette A., Fourrier H., Assessment of a remediation technique using the replacement of contaminated soils in kitchen gardens nearby a former lead smelter in Northern France, Science of the Total Environnement 401 (2008) 29-38.

[6] Tecninvest, Green cyber, Refinaria de Bio-Diesel, Estudo de Impacte Ambiental, Resumo Não Técnico, Relatório T 070106 Estudo n²602 A (2007) IV50-IV55.

[7] AGRIPRO AMBIENTE, Estudo de Impacte Ambiental dos Projectos de Conversão e Loteamento da Refinaria de Sines, Galp Energia, Volume I - Resumo Não Técnico (2008) 32-36.

[8] E-PRTR, European Pollutant Release and Transfer Register (2010): http://prtr .ec .europa. eu/Home . aspx.

[9] CCME, Canadian Environmental Quality Guidelines, http://ceqg-rcqe.ccme.ca/. 